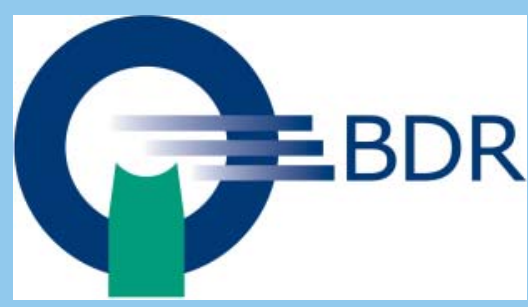

\title{
BDR-Rechtssprechungsreport Radiologie
}

\section{Bundesverfassungsgericht: MRT in der GKV nur für Radiologen}

Aller guten Dinge sind 3: Schon zum dritten Mal mussten sich die Verfassungshüter mit der Frage befassen, ob die Beschränkung der Kernspintomografie in der GKV-Versorgung auf Fachärzte für Radiologie (und Nuklearmedizin) mit dem Grundgesetz vereinbar ist. Das Bundesverfassungsgericht bleibt seiner Linie treu und hat die Verfassungsbeschwerde erneut nicht zur Entscheidung angenommen.

Zuerst versuchte es 1996 ein Orthopäde in Bayern. Nachdem er in der Universität zahlreiche Kernspintomografien auf orthopädischem Fachgebiet durchgeführt hatte, beantragte er die Genehmigung zur Durchführung und Abrechnung von MRT nach der Kernspintomografievereinbarung auf Grundlage des §135 Abs. 2 SGB V. Gegen die Ablehnung legte er Widerspruch, Klage und Berufung ein und blieb auch in der Revision zum Bundessozialgericht erfolglos. Gegen die Entscheidung des BSG vom 31.01.2001, Az. B 6 KA 24/00 R, legte er Verfassungsbeschwerde ein, die mit Beschluss vom 16.04.2004, Az. 1 BvR 1127/ 01, nicht zur Entscheidung angenommen wurde (DER RADIOLOGE 2004, M116).

Ebenso erging es einem Kardiologen aus Berlin mit seinem Antrag. Auch sein Weg durch die Instanzen war bis zum BSG (Urteil vom 11.10.2006, Az. B 6 KA 1/05 R) erfolglos und endete schließlich mit Nichtannahmebeschluss des Bundesverfassungsgerichts vom 08.07.2010, Az. 2 BvR 520/07.

Nachdem inzwischen auch in Berlin das Weiterbildungsrecht geändert worden war und der Berliner Kardiologe die Zusatzqualifikation Kernspintomografie - fachgebunden erworben hatte, versuchte er es erneut. Zunächst mit Erfolg. Das Sozialgericht Berlin verpflichtete die KV, dem Kläger die Abrech- nungsgenehmigung zu erteilen (SG Berlin Urt. v. 06.04.2011, Az. S 71 KA 151/11, DER RADIOLOGE 6/11 RRR 240). Doch schon das Landessozialgericht hob diese Entscheidung auf und wurde durch das BSG erneut bestätigt (Urt. 02.04.2014, Az. B 6 KA 23/13 R, DER RADIOLOGE 04/2014). Und wieder ging es zum Bundesverfassungsgericht und wieder wurde die Verfassungsbeschwerde nicht zur Entscheidung angenommen (Beschluss vom 02.05.2018, Az. 1 BvR 3024/ 14). Seit 20. Juni liegt nun die schriftliche Begründung dieser Entscheidung vor, die hoffentlich tatsächlich die letzte in dieser Sache sein sollte.

Die Voraussetzungen zur Durchführung von MRT-Untersuchungen sind in der Kernspintomografievereinbarung geregelt - dem sogenannten MRT-Führerschein. Danach dürfen nur Ärzte, die die Berechtigung zum Führen der Gebiets- oder Schwerpunktbezeichnung diagnostische Radiologie, Kinderradiologie, Neuroradiologie oder Nuklearmedizin vorweisen können, nach einer mindestens 24-monatigen, ganztägigen Tätigkeit in der kernspintomografischen Diagnostik unter Anleitung durch einen Weiterbildungsbefugten und nach erfolgreichem Kolloquium MRT-Leistungen erbringen.

Rechtsgrundlage der Kernspinvereinbarung ist $§ 135$ Abs. 2 Satz 4 SGB V. Dort ist den Vertragspartnern auf Bundesebene ausdrücklich die Befugnis eingeräumt worden, abweichend von den Vorgaben des Weiterbildungsrechts zur Sicherung der Qualität und der Wirtschaftlichkeit der Leistungserbringung Regelungen zu treffen, nach denen die Erbringung bestimmter medizinisch-technischer Leistungen den Fachärzten vorbehalten ist, für die diese Leistungen zum Kern ihres Fachgebiets gehören. Die Regelung ist auch unter dem Eindruck der ersten o.g. Entscheidung des BSG, auf das in der Gesetzesbegründung verwiesen wird, in das SGB V aufgenommen worden.

Erneut hat das Bundesverfassungsgericht klargestellt, dass diese gesetzliche Regelung und die darauf basierende Kernspinvereinbarung verfassungsrechtlich nicht zu beanstanden sind, insbesondere nicht gegen den Gleichbehandlungsgrundsatz verstoßen. Die Vorgaben sind zur Sicherung der Wirtschaftlichkeit gerechtfertigt, die auch der Qualitätssicherung der Versorgung durch sparsamen Einsatz von Ressourcen dient. Ausdrücklich verweist das Verfassungsgericht auch wieder auf den Stellenwert des Überweisungsvorbehalts und Mehraugenprinzips bei Trennung von Diagnostik und Therapie, das wirtschaftliche Fehlanreize vermeidet.

Solange die MRT nur für Radiologen als zum Kern des Fachgebiets zugehörig gilt, dürfte mit dieser Entscheidung nun tatsächlich ein Schlusspunkt für juristische Versuche der Öffnung der MRT für Organfächer gesetzt sein. Das erklärt die Vehemenz, mit der Kardiologen und andere Fächer die Weiterbildungsordnung „aufzuweichen“ versuchen.

Lohnt sich Berufspolitik? Nicht immer, aber immer öfter.

BVerfG, Beschl. v. 02.05.2018, Az. 1 BvR $3024 / 14$

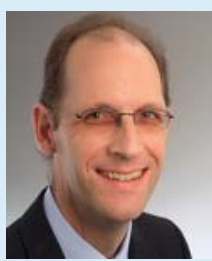

RA Markus Henkel München 